\title{
A contribuição da história oral na investigação e memória do rádio em Ponta Grossa (PR)
}

\author{
Sérgio Luiz GADINI ${ }^{1}$ \\ Felipe $\mathrm{ADAM}^{2}$ \\ Nadine Bianca SANSANA ${ }^{3}$
}

Resumo:

O presente estudo registra uma breve contribuição da história oral na investigação, memorialística, do rádio na Cidade de Ponta Grossa, Paraná. Os oito depoimentos são de profissionais e colaboradores que atuaram na radiodifusão regional ao longo do período entre 1960 e 2018. O estudo utiliza-se de referências teóricas que reconstituem o panorama histórico da radiodifusão (MIKAELLI, 2006; GADINI, 2009), além da metodologia da história oral (RIBEIRO, 2015). O trabalho infere que as relações familiares influenciam na escolha da futura profissão, bem como constata-se um apelo ao saudosismo em relação ao passado. Pelos relatos também se identifica o/a ouvinte como uma referência e desafio para horizontalizar a linguagem do rádio como função social e, ainda, opinião sobre a migração do AM para FM.

Palavras-chave: mídia regional; história da imprensa no Paraná; jornalismo regional; cultura e memória da radiodifusão paranaense.

\section{The contribution of oral history in investigation and memory of radio in Ponta Grossa (PR)}

\begin{abstract}
:
The present study records a brief contribution of oral history in radio, memorialistic, investigation in the city of Ponta Grossa, Paraná. The eight testimonies are of professionals and collaborators who worked in regional broadcasting over the period between 1960 and 2018. The study uses theoretical references that reconstruct the historical panorama of broadcasting (MIKAELLI, 2006; GADINI, 2009), in addition to the methodology of oral history (RIBEIRO, 2015). The work infers that family relationships influence the choice of future profession, as well as an appeal to homesickness in relation to the past. The reports also identify the listener as a reference and challenge to horizontalize the language of the radio as a social function, as well as an opinion on the migration from AM to FM.
\end{abstract}

Keywords: regional media; press history in Paraná; regional journalism; culture and memory of radio paranaense.

\section{La contribución de la historia oral en investigación y memoria de radio en Ponta Grossa (PR)}

Resumen:

\footnotetext{
1 Jornalista, professor doutor do Curso de Jornalismo e do Programa de Pós-Graduação (Mestrado) em Jornalismo da Universidade Estadual de Ponta Grossa (UEPG).E-mail: sergiogadini@yahoo.com.br.

${ }^{2}$ Jornalista e doutorando em Comunicação Social pela Pontifícia Universidade Católica do Rio Grande do Sul (PUC-RS), bolsista com financiamento da Coordenação de Aperfeiçoamento de Pessoal de Nível Superior (Capes), participou do presente estudo como mestre em Jornalismo pela Universidade Estadual de Ponta Grossa (UEPG). E-mail: felipeadam91@gmail.com.

${ }^{3}$ Jornalista formada pela Universidade Estadual de Ponta Grossa (UEPG), participou da presente pesquisa como bolsista de Iniciação Científica (PIBIC) CNPq/UEPG, entre 2018/2019. E-mail: nadinebsansana@ gmail.com.
} 
El presente estudio registra una breve contribución de la historia oral en la investigación radiofónica, memorialística, en la ciudad de Ponta Grossa, Paraná. Los ocho testimonios son de profesionales y colaboradores que trabajaron en la radiodifusión regional durante el período comprendido entre 1960 y 2018 . El estudio utiliza referencias teóricas que reconstruyen el panorama histórico de la radiodifusión (MIKAELLI, 2006; GADINI, 2009), además de la metodología de historia oral (RIBEIRO, 2015). El trabajo infiere que las relaciones familiares influyen en la elección de la profesión futura, así como un llamamiento a la nostalgia en relación con el pasado. Los informes también identifican al oyente como referente y desafío para horizontalizar el lenguaje de la radio como función social, así como una opinión sobre la migración de AM a FM.

Palabras clave: medios regionales; historia de la prensa en Paraná; periodismo regional; cultura y memoria de radio paranaense.

\section{Introdução}

Diante da raridade ou mesmo ausência de um acervo memorialístico regional organizado sobre fatos, atores e situações que envolvem as áreas de Comunicação e História, o presente estudo registra depoimentos de profissionais e colaboradores que atuaram no rádio de Ponta Grossa - cidade distante cerca de $110 \mathrm{~km}$ da capital Curitiba -, ao longo do período de 1960 a 2018. Por meio da gravação em áudio, a pesquisa objetiva contribuir com a sistematização organizada da memória, arquivo e história da comunicação regional no interior do Paraná. Além disso, é oportuno justificar a presente proposta por demandas atuais e futuras aos estudos em mídia e cultura regional.

A história da comunicação social na região dos Campos Gerais do Paraná ainda carece de uma organização ou, talvez, classificação conceitual, com o devido registro documental e depoimento de seus respectivos atores, capaz de servir de base e informação aos atuais e futuros pesquisadores da área, bem como à população em gerações futuras.

Como referenciais históricos, a pesquisa dialoga com alguns autores, como Mikaelli (2006), cujo trabalho permite reconstituir o cenário histórico das pioneiras estações locais Rádio Clube Pontagrossense, Rádio Central do Paraná, Rádio Difusora, Rádio Emissora Sant'Ana e Rádio Vila Velha/Pitangui/Nacional/CBN. Enquanto isso, um outro estudo sobre o tema (GADINI, 2009) destaca o relato da experiência da rádio de alto-falantes, que funcionou na principal avenida de Ponta Grossa, a Av. Dr. Vicente Machado, entre as décadas de 1940 e 1960

A partir da conversação com profissionais e colaboradores que atuaram em diferentes funções e espaços de mídia da região, o trabalho possibilita o lançamento de bases para uma organização sistematizada de um acervo da mídia nos Campos Gerais do Paraná. E, dessa forma, opta-se, aqui, como percurso metodológico, pelo conceito de história oral, apoiado nos estudos de Thompson (1998), Freitas (2006) e Ribeiro (2015). 
Como resultado, os diálogos possibilitaram debater o cenário do rádio pontagrossense. A primeira marca indica uma influência familiar, acompanhada pelo saudosismo de uma época passada (BOSI, 1994). Na sequência, percebe-se uma evolução do trabalho no contexto radiofônico, onde se pode inserir a relação dos ouvintes como uma estratégia midiática de horizontalizar a linguagem do rádio como função social e, por fim, um breve debate sobre a transição do AM para o FM (PRATA; DEL BIANCO, 2018).

\section{Metodologia}

O estudo emprega a metodologia da história oral, compreendida por Freitas (2006, p. 18) como "um método de pesquisa que utiliza a técnica da entrevista e outros procedimentos articulados entre si, no registro de narrativas da experiência humana". Tal metodologia foi escolhida por se tratar de uma sequência de narrativas, o que faz com que um dos objetivos do projeto seja alcançado, que é justamente registrar, por meio de entrevistas, depoimentos de profissionais e colaboradores que atuaram no rádio em Ponta Grossa (PR).

Para Freitas (2006), a estratégia metodológica contribui e faz parte da efetivação da história oral. Pode ser feito por meio da escrita e/ou da gravação, seja em áudio ou em vídeo. Entretanto, o uso de recursos eletrônicos faz com que a história oral passe a ser denominada "moderna história oral”, que é aquela "cujo método consiste na realização de depoimentos pessoais orais, por meio da técnica de entrevista que utiliza um gravador" (FREITAS, 2006, p. 26). As entrevistas seguem a lógica contemporânea da história oral, pois, dentre as oito realizadas, uma foi registrada em vídeo e as outras sete, gravadas em áudio.

A metodologia da história oral baseada em histórias de vidas busca recuperar a trajetória do entrevistado até o momento, considerando questões políticas, socioeconômicas e culturais (RIBEIRO, 2015). O trabalho busca contribuir com a memória comunicacional radiofônica de Ponta Grossa e, para isso, utiliza dos conhecimentos fornecidos por fontes orais.

É importante chamar atenção para o fato de que se a história oral é uma metodologia que produz (ou fabrica) um conjunto de fontes pode servir como referência para os mais diversos trabalhos sobre a história da mídia e do jornalismo. A pesquisa, neste caso, não se caracteriza pela coleta de dados ou informações guardadas ou acumuladas por um terceiro (indivíduo, grupo ou instituição). Pressupõe o ato criador dessa fonte pelo próprio pesquisador (RIBEIRO, 2015, p. 75). 
Diante da existência modesta de documentos, arquivos e registros sobre a história do rádio em Ponta Grossa, a metodologia da história oral se faz útil, pois, como explica Ribeiro (2015, p. 75), “os depoimentos ajudam a recuperar informações sobre fatos e processos que só podem ser conhecidos pela narrativa daqueles que os viveram diretamente ou daqueles que os presenciaram de alguma maneira". Isto é, recorre à memória, à lembrança daqueles que vivenciaram o que se pretende registrar.

Dessa forma, reforça-se o método biográfico, cuja história de vida de personagens auxilia na compreensão social de um período. "Mais que um desafio, escrever histórias de vida é uma possibilidade singular de mergulhar no passado, no íntimo dos entrevistados. É a dicotomia entre o real e o pessoal, a produção e a ruptura, a renovação do presente", explica Gobbi (2011, p. 84).

O percurso metodológico utilizado na pesquisa foi dividido em três etapas: (1) um levantamento empírico para identificar atores (em especial, profissionais) que trabalharam em produtos e veículos de mídia regional e podem contribuir com este mapeamento; (2) agendamento e realização de entrevistas (em áudio e/ou vídeo) com tais profissionais dispostos a participar da presente iniciativa e (3) início de um registro como contribuição da memória, arquivo e história da mídia regional em Ponta Grossa, por consequência, nos Campos Gerais do Paraná.

A primeira etapa considera uma breve pesquisa bibliográfica para localizar o que já foi produzido sobre a história do rádio na cidade de Ponta Grossa e, a partir disso, confirmou-se a falta de registros. O documento que traz mais detalhes da memória radiofônica pontagrossense é o livro História do Rádio AM de Ponta Grossa, escrito em 2006 pelo radialista Aldo Mikaelli. ${ }^{4}$

Como explica Ribeiro (2015, p. 79), “o primeiro passo na montagem de um programa de história oral é a escolha dos entrevistados". Algumas recomendações feitas por Ribeiro (2015) foram seguidas nesse processo de seleção de nomes para a realização desta pesquisa como, por exemplo, dar prioridade aos mais velhos, ${ }^{5}$ à diversidade, tanto das atividades

\footnotetext{
${ }^{4}$ Aldo Mikaelli faleceu no dia 12 de março de 2018, em Ponta Grossa/PR, onde residia.

${ }^{5}$ Aqui, Ribeiro (2015) explica também que na pesquisa em jornalismo deve se priorizar aqueles que exerceram a profissão (jornalismo); entretanto, na presente pesquisa, os jornalistas não foram prioridades, pois quando os entrevistados iniciaram a carreira no rádio, a obrigatoriedade do diploma não estava em vigor.
} 
exercidas pelos profissionais ${ }^{6}$ quanto de emissoras. A partir disso, foram identificados e listados alguns nomes para a (possível) realização das entrevistas.

Para entrar em contato com Mario Kreinski, foi utilizada a rede social Facebook. Já para contatar Julio Cesar Alves Pires, foi feita ligação à emissora para a qual ele trabalha. Para agendar a entrevista com Alcidina Ayres Rodrigues, Joel Oliveira, José Erondi Milléo, Paulo Roberto Ribeiro da Silva, Antônio Lourival dos Santos e Júlio César Moreira Francisquini, foi obtido o número de celular particular de cada um, a partir de indicações e contatos prévios ao estudo.

O próximo passo foi a elaboração das perguntas para entrevista. Como o objetivo era fazer com que o entrevistado não se sentisse incomodado e estivesse à vontade durante o depoimento, a construção do roteiro da entrevista se deu com perguntas mais simples, como explica Thompson (1998), ao discutir métodos de pesquisa:

As perguntas devem ser sempre tão simples e diretas quanto possível, em linguagem comum. Nunca faça perguntas complexas ou de duplo sentido em geral, apenas uma de suas metades será respondida e, em geral, não ficará claro qual delas. Evite um fraseado que leve a uma resposta indefinida (THOMPSON, 1998, p. 260).

Dessa maneira, o roteiro de questões foi dividido em quatro aspectos principais: 1) indivíduo - voltado para a trajetória profissional; 2) jornalístico - relacionado às pautas e transmissões; 3) técnico - sobre os equipamentos utilizados nas emissoras; e 4) migração do AM para FM, para saber sobre a aceitação, tanto do público quanto dos profissionais, perante a mudança.

$\mathrm{Na}$ terceira e última etapa do percurso metodológico, discute-se a contribuição da pesquisa para com a memória, arquivo e história da mídia regional em Ponta Grossa, por consequência, na região dos Campos Gerais do Paraná. Com as entrevistas realizadas e gravadas, o próximo passo foi, além de cuidar do arquivamento dos materiais, transcrever os depoimentos. Embora seja importante "o cuidado em não alterar o conteúdo do depoimento" (RIBEIRO, 2015, p. 86), durante as transcrições foi preciso adaptar a linguem oral à escrita, para dar uma melhor fluidez à leitura, a fim de que os vícios de linguagem presentes na fala não aparecessem no texto.

\footnotetext{
6 Nesta pesquisa entende-se como profissionais aqueles que atuam como técnicos (de equipamentos), apresentadores, narradores de futebol, apresentadores e comentaristas esportivos. Trata-se, pois, de uma delimitação da pesquisa, que buscou ouvir os referidos profissionais.
} 


\section{Análise e resultado das entrevistas}

O método da história oral, colocado em prática por meio do registro de narrativas, foi escolhido para esta pesquisa perante a ausência de arquivos e documentos sobre a história do rádio em Ponta Grossa. As conversas realizadas com os profissionais tiveram por objetivo contribuir com o registro e o acervo memorialístico radiofônico da cidade.

Com as perguntas já estruturadas e os profissionais definidos, as entrevistas foram realizadas. Vale ressaltar que o roteiro de entrevista apontado na etapa de metodologia, embora não tenha sido seguido à risca, contribuiu para a sistematização dos depoimentos. Dessa forma, após a realização e a transcrição dos oito relatos, observou-se que as declarações se concentraram em dois aspectos principais, com algumas subdivisões: 1) indivíduo: a) influência familiar; b) saudosismo perante ao período passado no rádio; 2) evolução do trabalho no contexto radiofônico: c) divisão dos depoimentos por décadas; d) função social; e) participação dos ouvintes e as relações com eles; f) transição do AM para o FM.

Tendo em vista que as primeiras perguntas direcionadas aos participantes eram relacionadas à trajetória profissional, os relatos iniciam com uma breve explicação de como cada um começou a ter contato com o rádio, não somente a partir do momento em que ingressaram no meio radiofônico, mas também o que os impulsionou para que manifestassem interesse na área.

$\mathrm{Na}$ primeira etapa dos depoimentos - voltada ao indivíduo - descobriu-se que a influência familiar foi uma condição muito forte, presente na trajetória dos profissionais. Contaram que, desde pequenos, ouviam rádio em casa por conta dos pais, considerando-se que esse era o único meio de comunicação ou o mais acessível da época, ${ }^{7}$ além de ser uma opção de entretenimento.

Meu pai escutava os jogos [de futebol] na antiga rádio Bandeirantes de São Paulo, quando ele ia para a varanda no sábado ou domingo à tarde escutar os jogos, a gente sentava do lado e ninguém podia conversar pra ele prestar atenção em tudo o que o locutor falava e eu ficava escutando com ele atentamente. Aí eu pensei comigo: um dia eu vou ser igual esse cara (OLIVEIRA, 2019).

Júlio César Moreira Francisquini, conhecido no rádio como Juca Francisquini, reforça que todas as informações que as pessoas recebiam eram somente por meio do rádio, pois a televisão ainda nem existia e, quando foi inventada, somente as pessoas com melhores

\footnotetext{
${ }^{7}$ Época de infância dos participantes: entre a década de 1940 e 1960.

${ }^{8}$ OLIVEIRA, Joel. Joel Oliveira: entrevista [04 abr. 2019]. Entrevistador: Nadine Bianca Sansana. Ponta Grossa, Paraná: Rádio Difusora, 2019. 1 arquivo .mp3 (39’51”)
} 
condições financeiras tinham acesso. "As pessoas, às vezes, não tinham em casa nem um toca-disco, um toca-fita, não tinham nada" (FRANCISQUINI, 2019). ${ }^{9}$

Quatro $^{10}$ dos oito relatos indicam que os participantes, ainda na infância, por algum contato diário, criaram um vínculo com a radiodifusão e o desejo de trabalhar no rádio. Os demais quatro participantes ${ }^{11}$ não relataram o mesmo desejo. "Nunca me passou pela cabeça ser locutor e eu nunca fui preparado pra isso", comenta Paulo Roberto Ribeiro da Silva (2019). ${ }^{12}$ Mas todos tinham o hábito diário de ouvir os programas e demonstravam gosto pelo meio radiofônico.

O segundo ponto observado na etapa relacionada ao indivíduo, nas conversas, aponta uma relação de saudosismo dos profissionais perante a época em que iniciaram os trabalhos no rádio. "Fazendo um comparativo ontem e hoje sobre as dificuldades de antes e as coisas fáceis de hoje, é diferente, mas pra mim foi mais gostoso o que ficou pra trás", diz José Erondi Milléo (2019). ${ }^{13}$

Alcidina Ayres Rodrigues (2019) ${ }^{14}$ explica que "antigamente" era muito melhor trabalhar no rádio porque, para se conseguir uma informação, o dever era correr atrás para tentar produzir a melhor notícia e, com isso, garantir maior audiência e o veículo conquistar uma certa referência. "Hoje não tem mais graça, a tua vizinha fica sabendo antes que você que trabalha no rádio, por causa da internet. Então é estranho essa tecnologia, essa modernidade, hoje parece que ficou muito fácil” (RODRIGUES, 2019).

Rodrigues questiona como que um veículo radiofônico pode fazer para ser o primeiro a dar uma informação diante dessa praticidade proporcionada pela internet. Ela afirma que a modernidade tecnológica facilitou a parte técnica do trabalho no rádio; em contrapartida, quanto ao conteúdo, o radialista precisa aprender a usar essa tecnologia para otimizar a produção e publicação das notícias.

Cada um, em algum momento do relato, comentou que sente saudades do período trabalhado no rádio e/ou que prefere a época passada. "O vínculo com outra época, a

\footnotetext{
9 FRANCISQUINI, Júlio César Moreira. Júlio César Moreira Francisquini: entrevista [11 jun. 2019]. Entrevistador: Nadine Bianca Sansana. Ponta Grossa, Paraná: Universidade Estadual de Ponta Grossa, 2019. 1 arquivo .mp3 (45'27')

${ }^{10}$ Alcidina Ayres Rodrigues, Erondi Milléo, Joel Oliveira e Antônio Lourival dos Santos.

${ }^{11}$ Julio Cesar Alves Pires, Júlio César Moreira Francisquini, Mario Kreinski e Paulo Roberto Ribeiro da Silva.

12 SILVA, Paulo Roberto Ribeiro da. Paulo Roberto Ribeiro da Silva: entrevista [15 abr. 2019]. Entrevistador: Nadine Bianca Sansana. Ponta Grossa, Paraná: Rádio T, 2019. 1 arquivo .mp3 (33’45”).

13 MILLÉO, José Erondi. José Erondi Milléo: entrevista [25 abr. 2019]. Entrevistador: Nadine Bianca Sansana. Ponta Grossa, Paraná: Rádio Sant'Ana, 2019. 1 arquivo .mp3 (1h 6’41”).

14 RODRIGUES, Alcidina Ayres. Alcidina Ayres Rodrigues: entrevista [11 abr. 2019]. Entrevistador: Nadine Bianca Sansana. Ponta Grossa, Paraná: Rádio Sant'Ana, 2019. 1 arquivo mp3 (44'33'’).
} 
consciência de ter suportado, compreendido muita coisa, traz para o ancião alegria e uma ocasião de mostrar sua competência. Sua vida ganha uma finalidade se encontrar ouvidos atentos, ressonância” (BOSI, 1994, p. 82).

A evolução das condições de trabalho no contexto radiofônico, bem como o pioneirismo das rádios, pode ser analisada a partir da leitura de Mikaelli (2006) e Gadini (2009). Entre as décadas de 1930 e 1960, os moradores de Ponta Grossa viveram a "era" da Rede de Alto-Falantes (RAF) dos Campos Gerais, instalada na praça central - Barão do Rio Branco - e distribuída em doze pontos estratégicos da cidade. Pelas ondas da RAF, a população se inteirava das informações, acompanhava apresentações, ouvia a respeito dos acontecimentos esportivos. "A RAF também representava a instituição de um espaço de sociabilidade, lazer e convivência pública. [...] um serviço de utilidade pública, uma mídia de radiodifusão comunitária, antes mesmo do surgimento da radiodifusão comercial em Ponta Grossa" (GADINI, 2009, p. 165).

Mikaelli (2006) menciona que os primórdios do rádio na cidade couberam à dupla Abílio Holzmann e Manoel Machuca. A partir da visão de ambos, o desejo de se ter um veículo de transmissão finalmente se concretizaria em janeiro de 1940, quando o som da Rádio Clube Pontagrossense irradiaria pela região dos Campos Gerais. Dois anos depois, a rádio apresentava um moderno auditório equipado nas instalações da rua XV de Novembro.

Conforme Mikaelli (2006), a segunda emissora instalada na cidade foi a Rádio Central do Paraná, em 1954, também por iniciativa de Abílio Holzmann e Manoel Machuca. No início, estava localizada na rua Augusto Ribas, no porão do Cine Teatro Ópera. À medida que acontecia a troca de diretores da rádio, a localização também ia mudando. Até que, em 2005, Roberto Alfredo Pietrobelli e Nilson Paulino de Oliveira assumiram a emissora que, desde 1984, encontrava-se na rua XV de Novembro. Atualmente, a Rádio Central do Paraná está localizada na rua Coronel Dulcídio, ainda sob direção de Nilson de Oliveira.

Em 1959, por iniciativa de Wallace Pina e Olavo Alberto de Carvalho, a terceira emissora instalada na cidade foi inaugurada: a Difusora, ${ }^{15}$ conforme descreve Mikaelli (2006). Inicialmente encontrava-se na avenida Vicente Machado, esquina com a rua Cel. Dulcídio. Naquela época, as radionovelas faziam muito sucesso, mas a Rádio Difusora se destacou quanto a isso, porque, em meados da década de 1960, produzia suas próprias novelas e

\footnotetext{
15 A Rádio Difusora operou em AM até o ano de 2017, quando realizou a migração para FM. Em 2020, a nomenclatura da rádio foi alterada para Lagoa Dourada FM 109.9, quando a emissora passou a ser operada pelo mesmo grupo que mantém a Rádio T FM 99.9, na cidade de Ponta Grossa/PR.
} 
seriados, conquistando um grande público. Ela ainda foi pioneira em fazer reportagens externas, ou seja, de qualquer ponto da cidade, direto do local do acontecimento.

Ainda de acordo com Mikaelli (2006), Iraci Trevisani Rosa, convidado pelo bispo auxiliar Dom Geraldo Pellanda, dirigiu, em 1962, o funcionamento da Rádio Sant'Ana, a quarta emissora a ser instalada em Ponta Grossa. Os estúdios ficavam no Colégio Diocesano São Luiz, no Centro da Cidade, em frente à Praça Barão do Rio Branco. Foram dois dias de festa pela inauguração da rádio, e artistas nacionais, como Agnaldo Rayol, compareceram à festividade. Antes de a rádio iniciar os trabalhos, o estúdio e os transmissores receberam a benção do bispo Dom Antonio Mazzarotto. ${ }^{16}$

A Rádio Vila Velha AM, quinta emissora da cidade, foi fundada por Iraci Trevisani Rosa, em 1967, segundo Mikaelli (2006). No ano de 1976, a Rádio Vila Velha AM (operando em ondas médias) se tornou a pioneira da cidade a fazer transmissões na Frequência Modulada (FM 94). Em 1993, a frequência da estação Onda Média foi transferida para a sociedade Rádio Pitangui, e Iraci Trevisani Rosa ficou responsável somente pela FM 94. Entre 1988 e 1993, a Rádio Pitangui ficou sob o comando do então prefeito, Pedro Wosgrau Filho (PDC e, em seguida, PSDB). Depois, o diretor negociou a emissora com um empresário de Curitiba, e ela passa a se denominar Rádio Nacional. Em 2001, como relata Mikaelli (2006), a Rádio Nacional foi integrada à rede Central Brasileira de Notícias (CBN), que opera pelo dial AM 1300.

Pode-se observar a evolução do meio radiofônico, a partir dos depoimentos fornecidos pelos oito participantes, que apresentam um panorama da realidade em que cada um conviveu, de acordo com as experiências. Milléo (2019) relata a década de 1960.

No setor policial eu ia e os policiais te passavam o chamado livro capa preta. Daí você pegava aquilo que podia e interessava e depois passava para a máquina de escrever. Depois que veio o golpe militar, tinha que ter 90 dias de arquivo. Você tirava os papeis porque as vezes tinha fiscalização. Hoje já nem arquiva muito porque hoje tem internet.

Milléo trabalhou no rádio durante o período da ditadura militar no Brasil (1964-1985). Em seus relatos, conta que na época do regime era tudo muito disciplinado e que, no setor policial, alguns atendiam bem e outros nem tanto. $\mathrm{O}$ radialista lembra que se usava muito o papel carbono para escrever o que iria ser apresentado no jornal, mas, muitas vezes, na

\footnotetext{
${ }^{16}$ Mikaelli (2006) aponta que o bispo auxiliar Dom Geraldo Pellanda e o bispo Dom Antonio Mazzarotto, ambos de Ponta Grossa, participaram das instalações da Rádio Sant'Ana na cidade porque a emissora é católica e ligada à Diocese de Ponta Grossa.
} 
correria dos trabalhos, as escritas eram feitas no lado errado do carbono e tudo acabava sendo perdido.

Julio Cesar Alves Pires e Mario Kreinski relembram as atividades empregadas na década de 1970. Tendo em vista que ambos têm conhecimento da técnica do rádio, as falas são ricas quanto aos equipamentos utilizados nas transmissões radiofônicas. Kreinski relata que fez manutenção na maioria das rádios da cidade, como a Rádio Central, a Clube, a Sant'Ana e, inclusive, a Alto Falante. "Eu praticamente remontei a Rede de Alto Falantes e hoje ela está lá no terminal [de ônibus]" (KREINSKI, 2019). ${ }^{17}$ Atualmente, Kreinski já está aposentado, mas Julio Cesar Alves Pires - na ocasião da entrevista - ainda atuava na área, na CBN. No depoimento, Pires (2019) $)^{18}$ conta a história da evolução dos equipamentos eletrônicos utilizados no rádio. No início da fala, descreve sobre os gravadores Deck e Akai, sendo este de rolo, utilizado para gravar os comerciais, entrevistas e até mesmo fazer edições.

Já existia a "casseteira", que rodava os comerciais e também músicas no ar. Pegava-se a fita K7, cortava-se trinta segundos, quarenta e cinco, até um minuto. Cortava essas fitas, então o comercial ia no tempo correto dentro da fita K7. Então, rodava ela, ela terminava, voltava no ponto do começo e assim a gente fazia o comercial da época (PIRES, 2019).

Logo em seguida, de acordo com Pires, o minidisc e o disquete começaram a ser usados nas gravações. E, depois de tudo isso, veio o computador, que, segundo ele, foi criado para facilitar o trabalho. Pires comenta que, com o computador, as pessoas passaram a ser mais "preguiçosas", tendo em vista que basta programar e a "máquina" faz tudo sozinha; embora ele mesmo chame a atenção para o fato de que, justamente por ser uma máquina, o computador às vezes dá problema e, ainda assim, precisa ser manipulado pelo ser humano (PIRES, 2019).

Antônio Lourival dos Santos - cujo apelido no rádio é Lourival Graxaim - e Juca Francisquini lembram a década de 1980. Santos $(2019)^{19}$ iniciou carreira como músico, tocava e cantava em emissoras locais em companhia do parceiro de dupla, até que, em 1982, começou a trabalhar nas rádios AM como apresentador de programas musicais. Francisquini destaca, em 1980, a quantidade de ídolos internacionais, como Madonna e Cyndi Lauper, e

\footnotetext{
17 KREINSKI, Mario. Mario Kreinski: entrevista [28 mar. 2019]. Entrevistador: Felipe Adam e Nadine Bianca Sansana. Ponta Grossa, Paraná: Universidade Estadual de Ponta Grossa, 2019. 1 arquivo .mp3 (25'22”).

18 PIRES, Julio Cesar Alves. Julio Cesar Alves Pires: entrevista [08 abr. 2019]. Entrevistador: Nadine Bianca Sansana. Ponta Grossa, Paraná: Rádio CBN, 2019. 1 arquivo .mp3 (25’32”).

19 SANTOS, Antônio Lourival dos. Antônio Lourival dos Santos: entrevista [11 jun. 2019]. Entrevistador: Nadine Bianca Sansana. Ponta Grossa, Paraná: Rádio Princesa, 2019. 1 arquivo .mp3 (11'19’).
} 
como era "vergonhoso" tocar música sertaneja nas rádios FM. "A década de 80 foi invadida pela música americana, não tocava música nacional, sertaneja, então, nem se ouvia falar, o que existia de sertanejo era mais aquele de raiz, mas em rádio AM" (FRANCISQUINI, 2019).

Pode-se, assim, compreender a transformação do rádio em Ponta Grossa a partir dos depoimentos dos entrevistados, tendo em vista que cada um comenta sobre sua experiência em determinada época. Assim como Pires e Kreinski recordam a década de 1970, Milléo relembra o decênio de 1980, bem como Santos e Francisquini. Por sua vez, Rodrigues e Silva falam um pouco sobre como eram as transmissões de notícias entre 1990 e 1999.

Eu sou do tempo do rádio que quando você estava na rua e você via um acidente, você ligava para a rádio e passava a informação. Você entrava em primeira mão com a notícia, parava tudo na rádio pra você entrar: não importava aonde você estava ou quem era você (RODRIGUES, 2019).

Rodrigues (2019) destaca ainda que não havia problemas quanto a quem fornecesse a informação, desde que a rádio fosse o primeiro veículo a transmitir. Já Silva (2019) conta um pouco sobre as transmissões das notícias esportivas. "Nos finais de semana eu ia nos estúdios da rádio, ouvia o locutor e ia passando informações do que ouvia pra ele. Eu era o que chamavam de informante de locutor e informante de plantão esportivo”, diz Silva (2019).

Joel Oliveira relata o período a partir do ano 2000, época em que começou a atuar nas rádios de Ponta Grossa. Na CBN trabalhou por 11 anos. Em 2019, quando concedeu a entrevista, era responsável pelo departamento de esportes da Rádio Difusora, além de trabalhar no setor comercial. Em seu depoimento, Oliveira (2019) enfatiza que sempre foi apresentador de programa esportivo e narrador. Conta que entre 1990 e 2018 trabalhou como terceirizado, dependendo de sua própria venda no rádio.

Eu fui o único cronista, jornalista esportivo de Ponta Grossa que fez todos os jogos do Operário em todos os campeonatos que ele participou desde janeiro de 2005 [...]. Eu fui em 2017 na série D do campeonato brasileiro. Teve jogo que eu fui sozinho, só estava eu de imprensa lá (OLIVEIRA, 2019).

Os depoimentos evidenciam o rádio pela função social. "O rádio, além de oferecer tudo o que vai ao ar, ele também oferece fora do ar, porque as pessoas ligam no rádio prá perguntar e o que a gente pode a gente faz, a gente fornece a informação", afirma Rodrigues (2019). Antônio Lourival dos Santos (2019) garante que o rádio leva “informação, música, diversão, utilidade pública" e isso faz dele um instrumento de importante interação social, até 
mesmo para o comércio, pois Santos comenta que nesses trinta anos dedicados ao rádio, sempre teve grandes anunciantes.

Mas nem todos os entrevistados afirmam que o rádio cumpre uma função social, alguns defendem que só se cumpriria a função social se estabelecesse um debate ou discussão acerca dos temas considerados mais importantes pela sociedade e também se tratassem as informações com mais seriedade. Apesar disso, a maioria dos relatos destaca que a função social do rádio deve fazer uma mescla entre o entretenimento e o jornalismo. "A função social do rádio é interagir com o público, é levar a música, a informação. E ela tem que estar aliada ao jornalismo, à música e levar entretenimento ao público", avalia Pires (2019).

Quanto à participação dos ouvintes, foi o tema que, por unanimidade, gerou um certo entusiasmo por parte dos entrevistados e o assunto mais exposto por todos. O roteiro da entrevista aborda, assim, a diferença da participação do público na época em que os profissionais iniciaram os trabalhos no rádio e nos tempos atuais. "Antigamente, o pessoal participava mais por cartinha. Quando eu estava nos anos 80 na outra emissora, eu recebia muita cartinha e o pessoal ligava bastante também no telefone da rádio. Agora, hoje em dia, é mais pelo WhatsApp mesmo", explica Santos (2019).

Os relatos enfatizam que os ouvintes nunca deixaram de entrar em contato com o radialista e com as rádios. Algumas falas mostram que a participação do público contribui para a construção da programação. "O ouvinte está bastante participativo. Antigamente, o ouvinte não tinha espaço, então o radialista fazia o que ele queria, hoje não. A primeira coisa que eu respeito, eu praticamente não faço programa, é o ouvinte", afirma Silva (2019). A aproximação do público com o radialista faz com que se crie uma relação de amizade, tanto que na maioria das narrativas aparece que, quando começaram a trabalhar, os profissionais recebiam até presentes de seus ouvintes. E, mesmo hoje, aqueles que atuam no rádio ainda são tratados com carinho e respeito pelo público.

Indagados se houve alguma resistência em querer mudar do AM para o FM, grande parte dos profissionais aceitou o processo. Outros, embora não tenham concordado, acabaram por acolher a ideia da migração. De acordo com Prata e Del Bianco (2018, p. 25), as razões apontadas pelos empresários foi aprimorar "a qualidade de som, garantir presença celular, aumentar o faturamento e viabilizar a continuidade da oferta do serviço. A mudança representa uma oportunidade para renovar a programação [...] além de ampliar a interação com a audiência a partir de dispositivos móveis”. Kreinski (2019) avalia a transição do AM para o FM: 
O rádio perde bastante com essa migração do AM para o FM. Hoje se você fizer uma análise do rádio diante da rádio digital, via internet [...] a rádio AM já deixou de existir. Hoje é mais coordenada as coisas pelo sistema de comunicação e as novas tecnologias implantadas no rádio. Mas a graça ainda está no bom e velho rádio (KREINSKI, 2019).

No Paraná, segundo estatística da Agência Nacional de Telecomunicações (Anatel), em 2019, existiam 687 emissoras de rádio: 188 AM comerciais, 200 FM comerciais, 17 FM educativas e 282 rádios comunitárias. Prata e Del Bianco (2018) efetivaram pesquisa com 15 das 71 emissoras que assinaram o termo de outorga no estado. Dos 15, cinco eram de Ponta Grossa: Massa FM, Rádio Clube Pontagrossense, Rádio Difusora, Rádio Sant'Ana e CBN. Muitos entrevistados observaram que a transição do AM para o FM colocou os profissionais da área a repensarem a programação radiofônica, já que a FM tem um alcance muito maior.

O AM estava sendo condenado, porque tinha rádio que não tinha mais AM. Muitas rádios entraram em um conflito porque migraram para a FM com cabeça de AM, daí não funcionou. Mas no meu entendimento foi uma transição boa. Não adianta ter uma programação boa se o som estiver ruim (FRANCISQUINI, 2019).

Conforme Prata e Del Bianco (2018, p. 246), as emissoras "possuem grandes expectativas com relação a melhorias que a mudança pode trazer, no entanto, elas parecem muito mais calcadas em algumas esperanças, do que baseadas efetivamente em dados de pesquisa e análise". Outro ponto da conclusão é de que "a migração foi uma exigência da legislação na área, então, foi uma questão de necessidade participar dessa transição" (PRATA; DEL BIANCO, 2018, p. 246).

\section{Considerações finais}

Pelo trabalho, destaca-se a oportunidade de conhecer um período da história da mídia radiofônica da cidade de Ponta Grossa (PR), a partir do olhar dos oito participantes acima relacionados. Para isso, foi importante a aproximação com as pessoas experientes, que abriram lembranças íntimas e, acima de tudo, confiaram no atendimento e na pesquisa aqui descrita.

A experiência de cada um deles, seja à frente do microfone seja nos bastidores da produção, foi fundamental para interpretar a transformação do rádio e as condições de trabalho nas últimas cinco décadas. Também é necessário observar que alguns aspectos foram analisados: identifica-se que a relação familiar, em diversos casos, foi um fator responsável 
em influenciar os futuros profissionais. Percebe-se, ainda, a partir dos relatos, marcas de experiências familiares vivenciadas por gerações anteriores, elemento intrínseco quando se resgata a memória de alguém com o intuito de recontar a história de um local ou personagem.

Por meio das reminiscências, expressas nas falas de entrevistados, também se pode compreender a relação dos ouvintes com o veículo rádio e cogitar que há uma maior proximidade entre ambos, diferente dos leitores com os jornais e dos telespectadores junto às emissoras televisivas. Como consequência, pode-se discutir a função social do rádio na atualidade. Por fim, a pesquisa configurou um espaço para que os participantes avaliassem a migração das rádios AM para FM: de um modo geral, todos os entrevistados concordaram com a mudança. Por variadas razões e motivos, o rádio é um veículo presente na vida cotidiana e, fundamentalmente, história recente da mídia, por certo, em todo o Brasil, como indicam diversos relatos e estudos na área. Afinal, registrar experiências de profissionais que atuaram em suporte técnico comunicacional (no caso, a radiodifusão, durante décadas passadas) é uma forma de registrar a história regional da mídia, a partir dos Campos Gerais do Paraná, ao Sul do Brasil.

\section{Referências}

BOSI, Ecléa. Memória e sociedade: lembranças de velhos. 3. ed. São Paulo: Companhia das Letras, 1994.

FREITAS, Sônia Maria de. História oral: Possibilidades e procedimentos. 2. ed. São Paulo: Associação Editorial Humanitas, 2006.

GADINI, Sérgio Luiz. Uma experiência de rádio comunitária nos anos 1940/60 em Ponta Grossa/PR: a Rede Alto Falantes como espaço de prestação de serviço público. In: WOITOWICZ, Karina Janz (org.). Recortes da mídia alternativa: histórias e memórias da comunicação no Brasil. Ponta Grossa: Ed. UEPG, 2009.

GOBBI, Maria Cristina. Método biográfico. In: DUARTE, Jorge; BARROS, Antonio (org.). Métodos e técnicas de pesquisa em comunicação. 2. ed. São Paulo: Atlas, 2011. p. 84-96.

MIKAELLI, Aldo. História do Rádio AM de Ponta Grossa. Curitiba: Imprensa Oficial, 2006.

PG se despede do radialista Aldo Mikaelli. JM [Jornal da Manhã], 12 mar. 2018. Disponível em: $\quad$ https://m.jornaldamanha.info/cotidiano/205210/pg-se-despede-do-radialista-aldomikaelli. Acesso em: 12 jul. 2019.

PRATA, Nair; DEL BIANCO, Nélia (org.). Migração do rádio AM para o FM: Avaliação de impacto e desafios frente à convergência tecnológica. Florianópolis: Insular, 2018. 
RIBEIRO, Ana Paula Goulart. A história oral nos estudos de jornalismo: algumas considerações teórico-metodológicas. Revista Contracampo, Niteroi, v. 32, n. 2. p. 73-90, abr./jul. 2015. Disponível em: https://periodicos.uff.br/contracampo/article/view/17543. Acesso em: 12 jul. 2019.

THOMPSON, Paul. A voz do passado: história oral. 2. ed. São Paulo: Paz e Terra, 1998.

\section{Fontes orais}

FRANCISQUINI, Júlio César Moreira. Júlio César Moreira Francisquini: entrevista [11 jun. 2019]. Entrevistador: Nadine Bianca Sansana. Ponta Grossa, Paraná: Universidade Estadual de Ponta Grossa, 2019. 1 arquivo .mp3 (45'27’').

KREINSKI, Mario. Mario Kreinski: entrevista [28 mar. 2019]. Entrevistadores: Felipe Adam e Nadine Bianca Sansana. Ponta Grossa, Paraná: Universidade Estadual de Ponta Grossa, 2019. 1 arquivo .mp3 (25'22”).

MILLÉO, José Erondi. José Erondi Milléo: entrevista [25 abr. 2019]. Entrevistador: Nadine Bianca Sansana. Ponta Grossa, Paraná: Rádio Sant'Ana, 2019. 1 arquivo .mp3 (1h 6’41”).

OLIVEIRA, Joel. Joel Oliveira: entrevista [04 abr. 2019]. Entrevistador: Nadine Bianca Sansana. Ponta Grossa, Paraná: Rádio Difusora, 2019. 1 arquivo .mp3 (39'51”).

PIRES, Julio Cesar Alves. Julio Cesar Alves Pires: entrevista [08 abr. 2019]. Entrevistador: Nadine Bianca Sansana. Ponta Grossa, Paraná: Rádio CBN, 2019. 1 arquivo .mp3 (25’32”).

RODRIGUES, Alcidina Ayres. Alcidina Ayres Rodrigues: entrevista [11 abr. 2019]. Entrevistador: Nadine Bianca Sansana. Ponta Grossa, Paraná: Rádio Sant’Ana, 2019. 1 arquivo mp3 (44'33").

SANTOS, Antônio Lourival dos. Antônio Lourival dos Santos: entrevista [11 jun. 2019]. Entrevistador: Nadine Bianca Sansana. Ponta Grossa, Paraná: Rádio Princesa, 2019. 1 arquivo .mp3 (11'19”).

SILVA, Paulo Roberto Ribeiro da. Paulo Roberto Ribeiro da Silva: entrevista [15 abr. 2019]. Entrevistador: Nadine Bianca Sansana. Ponta Grossa, Paraná: Rádio T, 2019. 1 arquivo .mp3 (33'45”).

Submetido em: 18.08.2020.

Aprovado em: 02.12.2021. 